\section{Vegetative Propagation of Eastern Redcedar by Stem Cuttings}

\author{
Paul H. Henry ${ }^{1}$, Frank A. Blazich ${ }^{2}$, and L. Eric Hinesley ${ }^{2}$ \\ Department of Horticultural Science, North Carolina State University, \\ Raleigh, NC 27695-7609
}

Additional index words. Juniperus virginiana. Christmas trees, conifer, ornamental, auxin, indolebutyric acid, genotype

\begin{abstract}
Studies were conducted to investigate the effects of season (timing), IBA application, genotype, crown position, type of cutting (straight vs. heel), cutting length, and stock plant age upon adventitious rooting of stem cuttings of eastern redcedar (Juniperus virginiana L.). Genotype had a strong influence on percent rooting, root count, and root length of 4-year-old trees. With trees of this age, percent rooting was maximized $(87 \%)$ with hardwood cuttings taken in January and treated with 5000 ppm IBA. Crown position from which cuttings were collected did not influence rooting. Straight cuttings, with or without a light wound, rooted at a significantly higher percentage $(\mathbf{7 8 \%})$ than heel cuttings $(52 \%)$. With 30 -year-old trees, cuttings from the lower third of the crown rooted at a significantly higher percentage $(67 \%)$ than cuttings from the middle third $(43 \%)$. Better rooting was obtained with straight $(68 \%)$ than heel $(47 \%)$ cuttings. Cutting length affected rooting, with root count and length highest in longer cuttings. Increased tree age reduced rooting, although cuttings from 40-yearold trees retained substantial rooting capacity. Chemical name used: $1 \mathrm{H}$ - indole-3-butyric acid (IBA).
\end{abstract}

Eastern redcedar, cultivated throughout the southeastern United States as a Christmas tree, is gaining popularity as an ornamental. The aromatic, red heartwood of the species is valuable for furniture, and its rot-resistant qualities make it useful for fenceposts and outdoor construction. Until recently, demand for trees of sawtimber diameter was met by cutting native stands. The number of large trees is diminishing, however, and interest has arisen in establishing cultivated plantations of the species.

Seedling populations of eastern redcedar are extremely variable in phenotype (Hall, 1952; Henderson et al., 1979; Van Haverbeck and Read, 1977), and offer considerable potential for selection. Vegetative propagation by stem cuttings would allow the ornamental and forestry industries to clone superior trees, likely increasing uniformity beyond that obtainable with seedling populations.

Studies investigating vegetative propagation of eastern redcedar (Doran, 1957; GilAlbert and Boix, 1978; Snyder, 1953) report optimal rooting with hardwood cuttings. Few

Received for publication 16 Dec. 1991. Accepted for publication 15 July 1992. This research was funded by the North-Carolina Agricultural Research Service (NCARS). Raleigh. NC 27695-7643. Use of trade names in this publication does not imply endorsement by the NCARS of products named nor criticism of similar ones not mentioned. From a thesis submitted by P.H.H. in partial fulfillment of the requirements for the PhD. The cost of publishing this paper was defrayed in part by the payment of page charges. Under postal regulations, this paper therefore must be hereby marked advertisement solely to indicate this fact. 'Graduate Research Assistant.

${ }^{2}$ Professor. data, however, are available on other factors that affect adventitious rooting. Therefore, the objective of this research was to investigate the effect of season (timing), auxin treatment, genotype, crown position, type of cutting (heel vs. straight), cutting length, and stock plant age on adventitious rooting of stem cuttings of eastern redcedar.

General procedures. Four-year-old trees were randomly selected from a site near Garner, N.C., and 10-, 30-, and 40-year-old trees from a site near Rolesville, N.C. All trees were of seedling origin from open-pollinated parents. Trees within a location were growing under uniform fertility.

Stem cuttings were collected, sealed in polyethylene bags, placed on ice, and transported to Raleigh. For experiments not initiated immediately, cuttings were stored overnight at $4 \mathrm{C}$. Stem bases were recut so that cuttings measured $15 \mathrm{~cm}$, and foliage was stripped from the basal $4 \mathrm{~cm}$. Wounding consisted of a single cut, $2.5 \mathrm{~cm}$ long, to a depth reaching secondary xylem and parallel to the long axis of the cutting; heel cuttings included a small piece of 2-year-old wood at the proximal end. IBA solutions (reagent grade IBA in $50 \%$ isopropanol) were applied by immersing the basal $3 \mathrm{~cm}$ of cuttings for 1 to 2 sec. Cuttings were air dried for 15 min and inserted to a depth of $4 \mathrm{~cm}$ in a raised greenhouse bench containing a moist rooting medium of 1 peat : 1 perlite $(\mathrm{v} / \mathrm{v})$. Cuttings were maintained under natural photoperiod at day/night cycles of $22 \pm 4 \mathrm{C} / 16$ $\pm 4 \mathrm{C}$, and misted daily for 4 sec every 6 min (0700 HR to sunset). Fungal contamination, reportedly a problem with the species (Schoeneweiss, 1969), was effectively controlled by spraying cuttings initially and weekly thereafter, alternating methyl [1-[(butylamino) carbonyl]-1 $H$ - benzimidazol-2yl] carbamate (benomyl) and 3a, 4, 7, 7a-tetrahydro-2-[(trichloromethyl)thiol] $-1 \quad H$ - isoindole-1,3(2 $H)$ - dione (captan) at rates of 1.8 and 2.4 g.liter ${ }^{-1}$, respectively.

Cuttings were harvested after 12 weeks and data recorded on percent rooting, root count, and root length or dry weight (dried at $70 \mathrm{C}$ for $48 \mathrm{~h}$ ); all data except rooting percentage were based on the actual number of cuttings that rooted (at least one primary root $\geq 2 \mathrm{~mm}$ long). Unless otherwise stated, the design within the propagation bed was a randomized complete block (RCB) with six blocks and 10 cuttings per treatment per block. Treatments were blocked to account for possible nonuniformity in mist nozzle spray patterns.

Four-year-old trees: Timing and auxin concentration (Expt. 1). Straight hardwood cuttings, removed from terminal portions of lateral branches in the upper third of tree crowns, were collected in mid-Oct. and midNov. 1988 and mid-Jan., mid-Feb., and midMar. 1989; softwood cuttings were collected in mid-July 1989. At each date, four cuttings were removed from each of 60 ortets. Following collection, cuttings were pooled over ortets, randomized, and treated with 0, 2500, 5000 , or 7500 ppm IBA. Data were subjected to analysis of variance (ANOVA) and regression analysis [PROC REG (SAS Institute, 1990)].

Four-year-old trees: Crown position, cutting type, and clonal variation (Expt. 2). Two studies were initiated in early Feb. 1988. The first investigated the effects of crown position and cutting type. Cuttings were removed from lateral branches originating at the lower, middle, or upper third of tree crowns; nine cuttings-three from each crown positionwere collected from each of 60 ortets. After collection, cuttings within a crown position were pooled over ortets, randomized, and prepared as 1) straight, 2) straight with a light wound, or 3) heel cuttings.

In the second study, 40 straight cuttings were collected from the middle crown of each of 10 ortets. The design within the propagation bed was a RCB with 10 treatments (ortets), four blocks, and 10 cuttings per treatment per block.

Cuttings in both studies were treated with 7500 ppm IBA, a concentration found to stimulate rooting in preliminary studies. Data were subjected to ANOVA, and treatment means were separated by the least significant difference (LSD) test $(P=0.05)$.

Thirty-year-old trees: Crown position, cutting type, and cutting length (Expt. 3). Three studies, each using the same two ortets, were initiated in mid-Jan. 1989. In the first, cuttings were removed from three crown positions (upper, middle, bottom), with 60 cuttings collected per crown position per ortet.

In the second, three cutting types (straight, straight with a light wound, and heel) were collected from the middle crowns of ortets. A total of 180 cuttings per tree was collected.

The third study involved two lengths of straight cuttings (15 and $25 \mathrm{~cm}$ ), with 120 


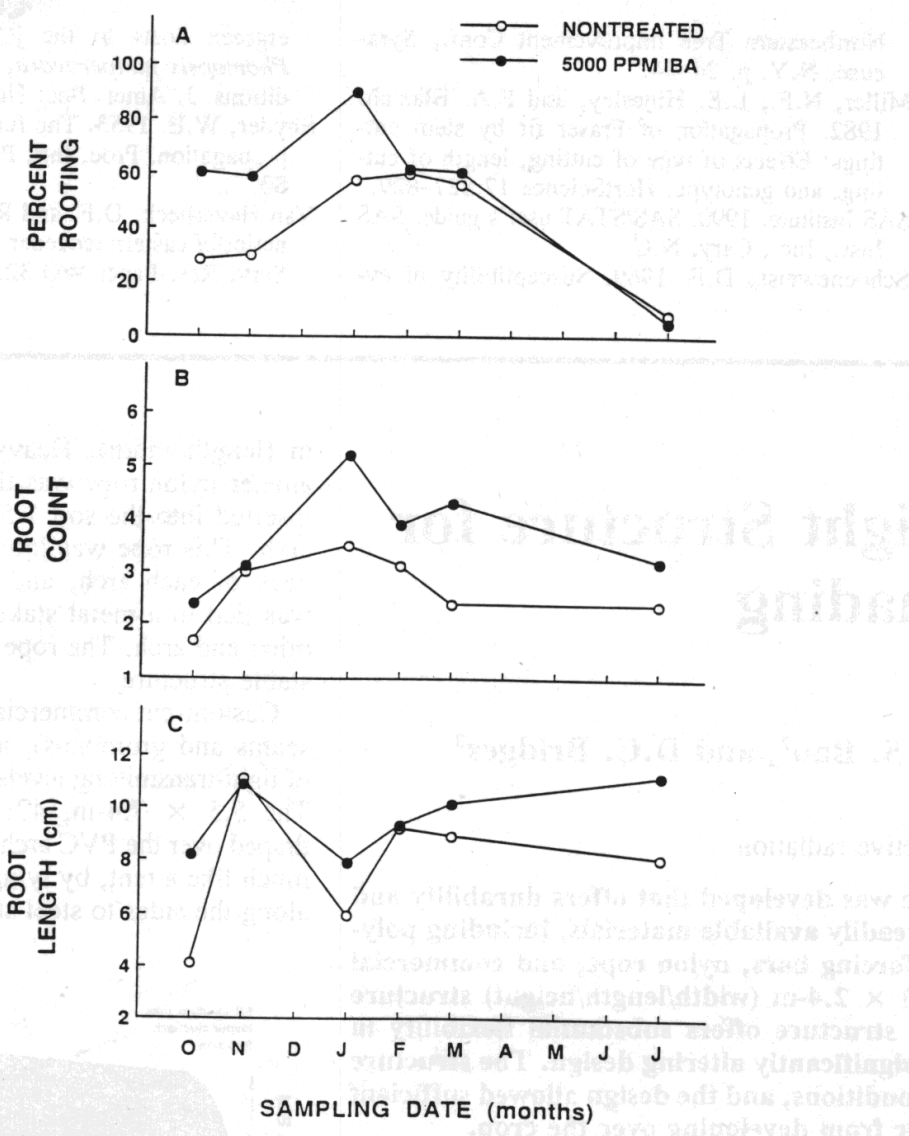

Fig. 1. Effect of sampling date (month) on adventitious rooting of nontreated $(0)$ and IBA-treated $(\bullet)$ stem cuttings from 4-year-old eastern redcedar (Expt. 1). (A) percent rooting; (B) root count; (C) root length, Root count and length are based on the actual number of cuttings that rooted.

cuttings collected from the middle crown of each tree.

In each study, cuttings within a treatment were pooled over ortets, randomized, and subsequently treated with 7500 ppm IBA. Data were subjected to ANOVA, and treatment means were separated by the LSD test $(P=0.05)$.

Tree age (Expt. 4). Two trees were selected within each of two age classes (10 and 40 years). In Feb. 1989, 40 straight cuttings were collected from lateral branches at the crown base. of each ortet. Cuttings were pooled over age groups, randomized, and subsequently treated with $7500 \mathrm{ppm}$ IBA. The design was a RCB with eight blocks and 10 cuttings per treatment (age class) per block. Data were subjected to ANOVA and treatment means separated by the $t$ test procedure (SAS Institute, 1990).

Four-year-old trees: Timing and auxin concentration (Expt. 1). Sampling date (month), auxin concentration, and the interaction between factors significantly $(P=$ 0.01 ) affected rooting response. Percent rooting and root count of nontreated cuttings $(0 \mathrm{ppm}$ IBA) increased during winter and were maximized in February $(62 \%)$ and January (3.6), respectively (Fig. $1 \mathrm{~A}$ and B). Root length, maximized in November at 11.3 $\mathrm{cm}$, displayed no discernible trend over sampling dates (Fig. 1C). Rooting percentage in July was $<10 \%$ (Fig. 1A), similar to data reported for softwood cuttings of other conifers (Hartmann et al., 1990).

For treated cuttings, efficacy of auxin varied with time of year that cuttings were collected (Fig. 1). Rooting percentage and root count of treated cuttings were maximized at $87 \%$ and 5.4, respectively, with cuttings taken in January and treated with $5000 \mathrm{ppm}$ IBA (Fig. $1 \mathrm{~A}$ and B). Compared with nontreated cuttings, 5000 ppm IBA increased root length only in October and July (Fig. 1C). An IBA concentration of $2500 \mathrm{ppm}$ resulted in poorer rooting, and response at $7500 \mathrm{ppm}$ was similar to that observed at $5000 \mathrm{ppm}$. In preliminary studies, IBA concentrations up to 20,000 ppm did not stimulate rooting beyond that obtained with $5000 \mathrm{ppm}$.

Four-year-old trees: Crown position, cutting type, and clonal variation (Expt. 2). Crown position had no effect on rooting percentage $(68 \%$ to $78 \%)$, root count $(4.2$ to $5.0)$, or length (8.2 to $9.2 \mathrm{~cm})$; also, there were no significant $(P=0.05)$ interactions between position and cutting type. Mean percent, count, and length, averaged over crown positions, were $73 \%, 4.6$, and 8.7 $\mathrm{cm}$, respectively.

Straight cuttings, with a light wound $(74 \%)$ or without $(82 \%)$, rooted at significantly $(P$ $=0.01$ ) higher percentages than heel cuttings (52\%). Cutting type did not affect root count (4.4 to 5.2$)$ or length $(7.5$ to $8.7 \mathrm{~cm})$. Despite poorer rooting, heel cuttings were more responsive to IBA than straight cuttings (data not presented). Two-year-old wood (heel cuttings) might contain auxin synergists or "rooting cofactors" not present in the current year's growth (Hartmann et al., 1990).

Genotype significantly affected rooting percentage $(P=0.01)$, root count $(P=$ $0.05)$, and length $(P=0.05)$. For these measures, genotype accounted for $0.53,0.30$, and 0.30 of total experimental variation, respectively. Percent rooting among clones ranged from $18 \%$ to $83 \%$. Genotypic influences on rooting have been noted in other conifers (Foster et al., 1984; Kiang and Garrett, 1975; Miller et al., 1982).

Thirty-year-old trees: Crown position, cutting type, and cutting length (Expt. 3). Cuttings from the middle third of ortets rooted less well $(43 \%)$ than cuttings from the bottom $(67 \%)$ or upper third $(56 \%)$. Cuttings from the base of mature conifers generally root best (Hackett, 1985). Type of cutting significantly $(P=0.05)$ affected rooting percentage. Again, straight cuttings, with $(65 \%)$ or without $(70 \%)$ a light wound, rooted at higher percentages than heel cuttings (47\%). Cutting length affected $(P=0.01)$ root count and dry weight but not rooting percentage. A higher root count (3.7 vs. 2.6) and dry weight (200 vs. $110 \mathrm{mg}$ ) were obtained with $25-\mathrm{cm}$ cuttings than with the shorter $15-\mathrm{cm}$ cuttings.

Tree age (Expt. 4). Percent rooting (83\% vs. $45 \%)$ and root count (4.2 vs. 2.6$)$ were significantly $(P=0.01)$ higher in 10 -yearold than 40-year-old trees. Substantial rooting of cuttings from the lower crown of 40year-old trees suggests that older trees having desirable characteristics may be cloned successfully.

Summary. Although young trees of eastern redcedar may be rooted at high percentages, response decreases with increased tree age. For trees of all ages, strong genotypic variation among clones makes successful vegetative propagation of any particular ortet uncertain. Unlike many coniferous species, eastern redcedar has no problem with plagiotropism; cuttings from lateral branches retain an upright growth habit after rooting. Research is needed to determine if vegetative propagules, as they age, fully retain the growth rate and phenotypic characteristics associated with the parent tree.

\section{Literature Cited}

Doran, W.L. 1957. Propagation of woody plants by cuttings. Univ. of Massachusetts Agr. Expt. Sta. Bul. 491, Amhersrt.

Foster, G.S., R.K. Campbell, and W.T. Adams. 1984. Heritability, gain, and C effects in rooting of western hemlock cuttings. Can. J. For. Res. 14:628-638.

Gil-Albert, F. and E. Boix. 1978. Effect of treatment with IBA on rooting of ornamental conifers. Acta Hort. 79:63-77.

Hackett, W.P. 1985. Juvenility, maturation, and rejuvenation in woody plants. Hort. Rev. 7:109155.

Hall, M.T. 1952. Variation and hybridization in Juniperus. Ann. Missouri Bot. Garden 39:164.

Hartmann, H.T., D.E. Kester, and F.T. Davies, Jr. 1990. Plant propagation, principles and 
practices. 5th ed. Prentice-Hall, Englewood Cliffs, N.J.

Henderson, L.T., T.F. Koppe, and R.E. Schoenike. 1979. Ten-year evaluation of a seed source study of eastern redcedar in South Carolina. Tree Planters' Notes 30(1):3-6.

Kiang, Y.T. and P.W. Garrett. 1975. Successful rooting of eastern white pine cuttings from a 17 -year-old provenance planting. Proc. 22nd
Northeastern Tree Improvement Conf., Syracuse, N.Y. p. 24-34.

Miller, N.F., L.E. Hinesley, and F.A. Blazich. 1982. Propagation of Fraser fir by stem cuttings: Effects of type of cutting, length of cutting, and genotype. HortScience 17:827-829.

SAS Institute. 1990. SAS/STAT user's guide. SAS Inst., Inc., Cary, N.C.

Schoeneweiss, D.F. 1969. Susceptibility of ev- ergreen hosts to the juniper blight fungus, Phomopsis juniperovora, under epidemic conditions. J. Amer. Soc. Hort. Sci. 94:609-611. Snyder, W.E. 1953. The fundamentals of juniper propagation. Proc. Intl. Plant Prop. Soc. 3:6780.

Van Haverbeck, D.F. and R.A. Read. 1977. Genetics of eastern redcedar. U.S. Dept. Agr. For. Serv. Res. Paper WO-32, Washington, D.C. 